\title{
Middle ear and hearing disorders of schoolchildren aged 7-10 years in South Sinai, Egypt
}

\author{
G. Yamamah, ${ }^{1}$ A. Mabrouk, ${ }^{2}$ E. Ghorab, ${ }^{3}$ M. Ahmady and H. Abdulsalam ${ }^{2}$
}

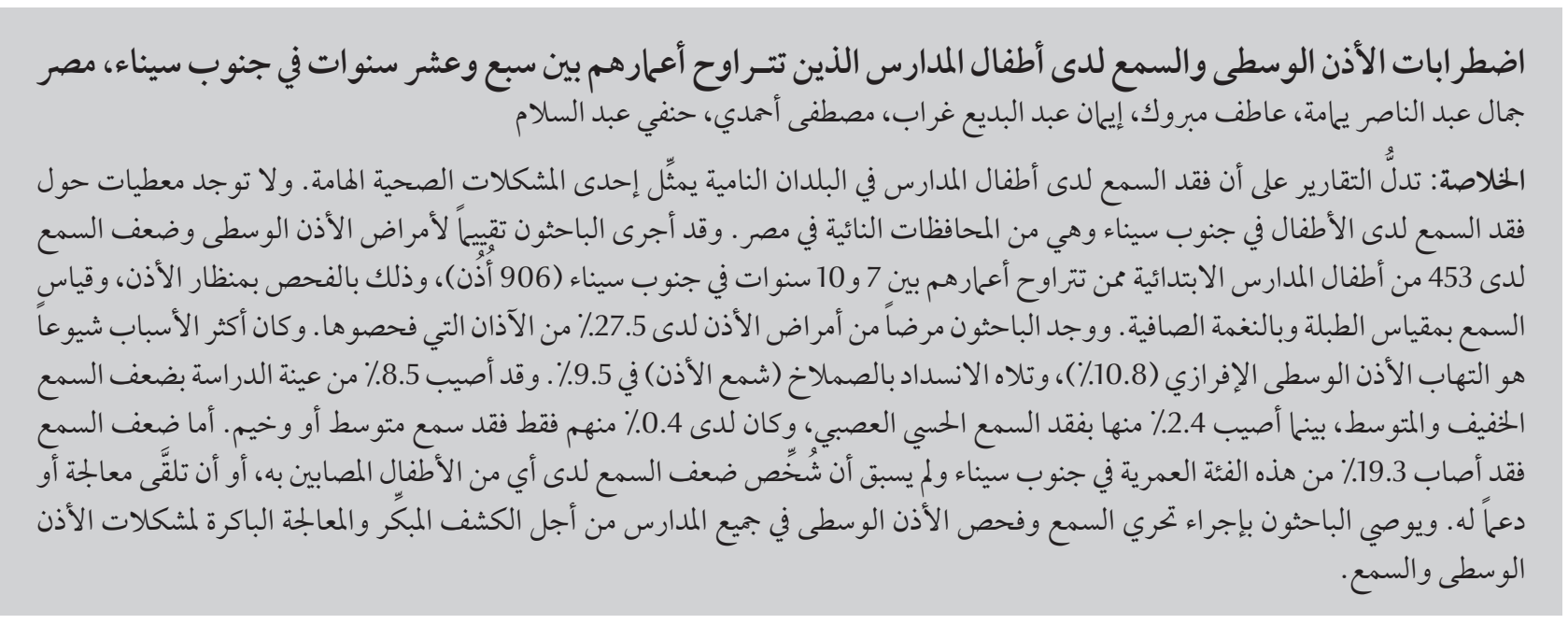

ABSTRACT Hearing loss among schoolchildren in developing countries is reported to be a significant health problem. Data on child hearing loss in South Sinai, a remote governorate of Egypt, are lacking. Middle ear diseases and hearing impairment were assessed among 453 primary-school children aged 7-10 years in South Sinai (906 ears). Otoscopic examination, tympanometry and pure tone audiometry (PTA) were done. Ear disease was found in $27.5 \%$ of the ears examined. The commonest cause was secretory otitis media (10.8\%), followed by occluded earwax (9.5\%). Mild and moderate hearing loss affected $8.5 \%$ of the sample, while sensorineural hearing loss affected 2.4\%; only $0.4 \%$ had moderate and severe hearing loss. Hearing impairment affects $19.3 \%$ of this age group in South Sinai. None of the children with hearing impairment had been previously diagnosed or was receiving treatment and support. Hearing and middle ear screening at schools is recommended for early detection and management of middle ear and hearing problems.

\section{Troubles de l'oreille moyenne et de l'audition chez des écoliers âgés de 7 à 10 ans au Sud Sinaï (Égypte)}

RÉSUMÉ La perte d'audition chez les écoliers de pays en développement est décrite comme un problème de santé important, mais les données sur la perte d'audition chez l'enfant au Sud Sinaï, un gouvernorat égyptien reculé, sont rares. Les affections de l'oreille moyenne et les déficiences auditives ont été évaluées chez 453 écoliers âgés de 7 à 10 ans au Sud Sinaï (soit 906 oreilles examinées). Un examen otoscopique, une tympanométrie et une audiométrie tonale ont été réalisés. Des affections de l'oreille ont été observées chez $27,5 \%$ des oreilles examinées. La cause la plus fréquente était une otite sécrétoire (10,8 \%), suivie par un bouchon de cérumen (9,5\%). Les pertes de l'audition légères à modérées touchaient 8,5\% des enfants de l'échantillon, alors qu'une surdité neurosensorielle affectait 2,4\% d'entre eux. Seul 0,4 \% des enfants souffrait de pertes auditives modérées à sévères. Les déficiences auditives concernaient 19,3\% de ce groupe d'âge au Sud Sinaï, mais aucun des enfants en présentant une n'avait auparavant reçu un diagnostic, un traitement, ni même un appui approprié. Un examen de l'audition et de l'oreille moyenne dans les écoles est recommandé, pour permettre un dépistage et une prise en charge précoces de ces affections.

'Paediatrics Department, National Research Centre, Cairo, Egypt (Correspondence to G. Yamamah: Yamamahg@hotmail.com). ${ }^{2}$ Ear, Nose and Throat Department; ${ }^{3}$ Audiology Department, Hearing and Speech Institute, Cairo Egypt. 


\section{Introduction}

Slight/mild bilateral hearing loss is reported to be a prevalent childhood condition that may result in significant language and academic deficits [1]. Most children with hearing loss will show significant learning difficulties when they reach the third year of school (around 9 years of age) and the symptoms of a hearing loss can sometimes be mistaken for an attention deficit problem [2].

Studies among schoolchildren in the developing world suggest that hearing loss is a significant health problem [3-5]. However, such children are rarely screened for hearing loss either during routine clinical examination or at school [3]. This is likely due to lack of awareness among parents, school authorities and healthcare providers about the adverse effects of mild hearing loss [3].

South Sinai is a remote and arid area in Egypt. The population is different (culturally and ethnically) from other governorates in the Nile valley [6]. There are a lack of specialized health services in South Sinai; there are no audiometry or tympanometry facilities in the whole governorate and no audiologist. Education among parents is quite poor and they lack awareness of audiology and how to manage hearing disorders for their children.

Given thelack of anyprevious studies in the governorate on hearing in schoolchildren and hence a lack of data on the extent of hearing problems, the aim of this work was to screen primary-school children in South Sinai for middle-ear diseases and hearing impairment and to detect the main causes of hearing loss.

\section{Methods}

\section{Sample}

A cross-sectional study was conducted during October 2009 to February 2010 to screen for otological and hearing disorders in primary-school children in
South Sinai. Children in grades 2 and 3 were selected, representing ages 7 to 10 years. This age group was selected because voluntary threshold could be easily measured, it is the age when middle ear problems should have resolved and is the age when education starts to require more cooperation and input from children.

Sample size was calculated using the equation published by DawsonSaunders and Trapp [7]:

$$
n=\frac{\mathrm{t}^{2} \times \mathrm{p} \times(1-\mathrm{p})}{\mathrm{m}^{2}}
$$

where $n=$ required sample size, $\mathrm{t}=$ confidence level at 95\% (standard value of 1.96), $p=$ estimated prevalence of the problem in the project area, $\mathrm{m}=$ margin of error at $5 \%$ (standard value of 0.05 ). The total population of South Sinai children aged $7-10$ years was 8010 (according to the report of the Directorate of the Ministry of Health, 2008), the published prevalence of the disorder worldwide was $5 \%-13 \%$. Thus the sample size required for the disorder prevalence range was between 95 and 210 children.

Four of 8 cities in South Sinai were selected randomly: Abu Redeis (Area 1), Ras Sidre (Area 2), Nuweiba (Area 3) and El Tur (Area 4) and then 4 schools were selected randomly, one from each city. As the number of schools and students differed between areas, selection of the students was made proportionate to the size of the area according to the estimated number of schools or students in each area from governmental records.

We increased the sample size to increase the power of the study. Thus the study included 453 children, 228 (50.3\%) males and 225 (49.7\%) females: 78 from area 1, 64 from area 2, 117 from area 3 and 194 from area 4. For each child, testing was done for both ears (906 ears tested): 156, 128, 234 and 388 ears from examination in areas $1,2,3$ and 4 respectively
We informed the health and education authorities before starting the study and they informed the children and their parents via an information package sent home from school. We explained the benefits of the tests and of fitting hearing aids for indicated cases and that the procedures were not painful nor invasive. There were no refusals to participate and all parents gave their informed consent. All the children underwent otoscopy and audiometry screening.

\section{Data collection}

The tests conducted included otoscopic examination, tympanometry and pure tone audiometry (PTA). One-stage audiometric examination was conducted following a daily check of the immittance meter and pure-tone audiometer.

Otoscopy: The external ear canals were examined with an otoscope to check for any external ear abnormality, foreign body or impacted earwax. The tympanic membranes were examined for congestion, bulging or retraction, opacity, perforation and mobility.

If earwax was not causing occlusion, tympanometry and PTA were conducted; if wax was causing occlusion, only PTA was done.

Tympanometry: Tympanometric evaluation was conducted using an immittance meter, model AT 235, and a portable hand-held tympanometer, model Danplex.

PTA: Audiometric testing was performed in the quietest section in each school using a calibrated pure tone audiometer, model AD226, with TDH-39 earphones .Tests were carried out only when the noise level meter reading was $<45 \mathrm{dBA}$.

The tests were done by specialists in audiology affiliated to the Hearing and Speech Institute in Cairo and the sheets were revised by audiology professors of the institute.

A pure tone average up to $15 \mathrm{db} \mathrm{HL}$ at frequencies of $0.5-4.0 \mathrm{kHz}$ was considered normal hearing [8]. In addition, 
because testing was not done in a sound room, hearing up to $20 \mathrm{db} \mathrm{HL}$ was considered normal. The American standard reference adopted by the American Speech-Language-Hearing Association (ASLHA) was used to assess the degree of hearing loss [9]. It uses the following degrees of hearing loss and decibel cut-offs (indicating the softest intensity that sound is perceived): slight hearing loss (21-25 db HL), mild (25-40 db HL), moderate (40-55 db $\mathrm{HL})$, moderately severe (55-70 db), severe (70-90 db) and profound (> $90 \mathrm{db})$.

\section{Analysis}

The data were analysed using SPSS, version 11 . Frequency of hearing problems and mean and standard deviation (SD) of hearing thresholds at different frequencies are presented. The Student t-test, chi-squared tests and ANOVA were done. Significance was set at the $5 \%$ level.

\section{Results}

For each child otoscopic examination was done followed by tympanometry and PTA. According to the results of otoscopic examination and tympanometry, children were divided into 5 categories:

- Group 1: tympanogram reflecting normal middle ear function

- Group 2: tympanogram indicating secretory otitis media
- Group 3: tympanogram indicating Eustachian tube dysfunction

- Group 4: occluding earwax

- Group 5: perforated tympanic membrane with or without ear discharge

Table 1 presents ear examination data of each group. Statistical analysis showed nonsignificant difference between males and females. In all 27.5\% of the ears examined showed positive findings, the most prevalent middle ear problem was secretory otitis media (10.4\%) (group 2).

Table 2 shows the distribution of children according to middle ear findings in the studied areas. There was a statistically significant difference in the presence of different middle ear problems in the different areas $\left(\chi^{2}=46.05\right.$, $P<0.001)$. In areas 2 and 4 the main abnormality was occluding earwax, while in areas 1 and 3 secretory otitis media was the most common problem. Although more boys had perforated tympanic membrane and more girls more occluding earwax, the difference was not statistically significant $\left(\chi^{2}=\right.$ $1.45, P>0.05)$.

Table 3 shows the hearing thresholds at different frequencies in the different groups. The worst hearing level was detected in children with perforated tympanic membrane, followed by secretory otitis media (in frequencies up to $1000 \mathrm{~Hz}$ ). Post-hoc test analysis showed statistically significant differences in hearing level between most groups at all frequencies except between Eustachian tube disease and occluding earwax.
Hearing level categories among ears examined showed that $731(80.7 \%)$ ears had normal hearing (up to $20 \mathrm{dBn}$ HL); 98 (10.8\%) had minimal hearing loss (up to $25 \mathrm{dBn} \mathrm{HL}$ ); 73 (8.1\%) have mild hearing loss (up to $40 \mathrm{dBn} \mathrm{HL}$ ) and $4(0.4 \%)$ had moderate and severe hearing loss (> $40 \mathrm{dBn} \mathrm{HL}$ ).

In all $27.5 \%$ of ears showed abnormality in otoscopic examination or tympanometry. Bilateral affection (23.2\%) was more common than unilateral affection (10.6\%). Only $10.8 \%$ of ears had minimal hearing loss and $8.1 \%$ mild ( $8.5 \%$ overall). The number of ears showing any degree of sensorineural hearing loss were 22 ears (2.4\%); even the 4 cases with moderate or severe hearing loss had a unilateral complaint. It was also evident that children with hearing loss greater than mild were not enrolled in ordinary education. No child was wearing a hearing aid in any of the studied groups, although 4 were in need of one.

\section{Discussion}

Ear problems were found in $27.5 \%$ of the ears examined (Table 1). The most common cause was secretory otitis media (10.8\%) followed by occluded wax (9.5\%). The most common cause of hearing loss in children is otitis media [10]. The odds of developing at least 1 episode of otitis media has been reported to be $63 \%-85 \%$ by 12 months of age and 66\%-99\% by 24 months [10].

\begin{tabular}{llrrrrr}
\hline Table 1 Ear examination data & & & & & \\
Group & Ear category & Males & Females & $\boldsymbol{P}$-value & Total & \% of total \\
& & No. & No. & & No. & \\
1 & Normal ears & 331 & 327 & & 658 & 72.6 \\
2 & Secretory otitis media & 50 & 44 & 0.435 & 94 & 10.4 \\
3 & Eustachian tube disease & 33 & 30 & 0.664 & 63 & 7.0 \\
4 & Earwax & 39 & 47 & 0.354 & 86 & 9.5 \\
5 & Perforated tympanic membrane & 3 & 2 & 0.684 & 5 & 0.6 \\
$2+3+4+5$ & Ears with disorders & 125 & 123 & 0.824 & 248 & 27.4 \\
Total & & 456 & 450 & & 906 & 100.0 \\
\hline
\end{tabular}




\begin{tabular}{|c|c|c|c|c|c|c|}
\hline \multirow[t]{2}{*}{ Area } & $\begin{array}{c}\text { Group } 1 \\
\text { (Normal ears) }\end{array}$ & $\begin{array}{c}\text { Group } 2 \\
\text { (SOM) }\end{array}$ & $\begin{array}{l}\text { Group } 3 \\
\text { (ETD) }\end{array}$ & $\begin{array}{l}\text { Group } 4 \\
\text { (Earwax) }\end{array}$ & $\begin{array}{c}\text { Group } 5 \\
\text { (Perforated TM) }\end{array}$ & Total \\
\hline & No. (\%) & No. (\%) & No. $(\%)$ & No. (\%) & No. (\%) & No. (\%) \\
\hline Area 1 (Abu Redeis) & $90(57.7)$ & 29 (18.6) & $17(10.9)$ & $20(12.8)$ & $0(0.0)$ & $156(100)$ \\
\hline Area 2 (Ras Sidre) & $94(73.4)$ & $9(7.0)$ & $4(3.1)$ & 19 (14.8) & $2(1.6)$ & $128(100)$ \\
\hline Area 3 (Nuweiba) & $165(70.5)$ & $32(13.7)$ & $17(7.3)$ & $19(8.1)$ & $1(0.4)$ & $234(100)$ \\
\hline Area 4 (El-Tur) & $309(79.6)$ & $24(6.2)$ & $25(6.4)$ & $28(7.2)$ & $2(0.5)$ & $388(100)$ \\
\hline Total & $658(72.5)$ & $94(10.4)$ & $63(7.0)$ & $86(9.5)$ & $5(0.6)$ & $906(100)$ \\
\hline
\end{tabular}

$\chi^{2}=46.05, P<0.001$ for difference between areas

$S O M=$ secretory otitis media ETD = eustachian tube disease $; M=$ tympanic membrane .

The percentage of days with middle ear effusion has been reported to be $5 \%-27 \%$ during the first year of life and $6 \%-78 \%$ during the second year. Rates are highest between 6 and 20 months. After 2 years of age, the incidence and prevalence of otitis media declines progressively, although the disease remains relatively common into the early school-age years [10].

Secretory otitis media was highly prevalent in areas 1 (Abu Redeis) and 3 (Nuweiba) with $18.6 \%$ and $13.7 \%$ prevalence respectively. The inhabitants of these 2 areas are mainly Bedouins. Factors believed to affect the occurrence of otitis media include age, gender, race, genetic background and socioeconomic status [10].

The hearing loss among schoolchildren in the current study was predominantly minimal ( $10.8 \%$ of ears) or mild
( $8.1 \%$ of ears). In a study of Hispanic children, it was reported that slight/mild hearing loss (16-40 dB) may affect as many as $3 \%-15 \%$ of primary-school children [1], and it is unlikely to be easily detected because the handicap is associated more with receptive rather than expressive linguistic skills [11]. The prevalence of minimal sensorineural hearing loss in school-aged children has been reported to be $5.4 \%$ in an American study [12]. In a Saudi Arabian study the prevalence of hearing loss in school-aged children ( $5-15$ years) was $13 \%$ and the commonest cause was secretory otitis media [13]. On the other hand, another study in Saudi Arabia reported a prevalence of hearing loss in schoolchildren 6-12 years of only $4.4 \%$ ( $1.7 \%$ mild, $2 \%$ moderate and $0.7 \%$ severe) [14].

In Egypt; the prevalence of hearing loss in schoolchildren (6-12 years) was reported to be $5.3 \%$ in Alexandria [15] and $4.5 \%$ in rural areas [16]. Another study in Ismailia governorate found hearing loss among $13.7 \%$ of schoolchildren, but they only used tympanometry to test for middle ear diseases [17]. Recently, a national household survey reported a prevalence of hearing loss of almost $10 \%$ in children aged $5-14$ years, $79.4 \%$ of which was mild, i.e. almost $8 \%$ of the study group had mild loss which is similar to our results, although their study was home-based and so did not only involve children in school [18].

Bilateral affection (23.2\%) was more common than unilateral affection (10.6\%) in the present study. An almost similar finding was reported by Hussein who found that $77.27 \%$ of cases with hearing problems were bilateral while $22.73 \%$ had unilateral affection [17]. In our study, sensorineural hearing loss was found in 22 ears (2.4\% of the total, $19.3 \%$ of all ears studied showed hearing

\begin{tabular}{|c|c|c|c|c|c|c|c|}
\hline \multirow[t]{2}{*}{ Group } & Ear category & $\begin{array}{l}\text { PTA } 250 \mathrm{~Hz} \\
\text { (dBn HL) }\end{array}$ & $\begin{array}{l}\text { PTA } 500 \mathrm{~Hz} \\
\text { (dBn HL) }\end{array}$ & $\begin{array}{l}\text { PTA } 1000 \mathrm{~Hz} \\
\text { (dBn HL) }\end{array}$ & $\begin{array}{l}\text { PTA } 2000 \mathrm{~Hz} \\
\text { (dBn HL) }\end{array}$ & $\begin{array}{l}\text { PTA } 4000 \mathrm{~Hz} \\
\text { (dBn HL) }\end{array}$ & $\begin{array}{l}\text { PTA } 8000 \mathrm{~Hz} \\
\text { (dBn HL) }\end{array}$ \\
\hline & & Mean (SD) & Mean (SD) & Mean (SD) & Mean (SD) & Mean (SD) & Mean (SD) \\
\hline 1 & Normal ears & $18.14(3.87)$ & $15.33(3.93)$ & 14.77 (3.99) & $15.67(5.20)$ & $14.18(5.59)$ & $14.90(5.72)$ \\
\hline 2 & Secretory otitis media & $28.35(4.48)$ & $28.19(4.00)$ & $27.07(4.94)$ & 25.15 (3.97) & $22.97(3.97)$ & $21.27(3.87)$ \\
\hline 3 & $\begin{array}{l}\text { Eustachian tube } \\
\text { disease }\end{array}$ & $20.63(5.71)$ & $18.17(5.62)$ & $18.25(5.61)$ & $18.41(5.87)$ & $16.26(4.83)$ & $16.19(5.05)$ \\
\hline 4 & Earwax & $21.97(6.47)$ & $20.98(7.42)$ & 20.89 (8.13) & $20.29(9.49)$ & $18.61(10.27)$ & $18.77(12.24)$ \\
\hline 5 & $\begin{array}{l}\text { Perforated tympanic } \\
\text { membrane }\end{array}$ & $35.00(6.12)$ & $33.00(9.08)$ & $33.00(9.74)$ & $30.00(14.14)$ & $27.00(13.03)$ & $25.00(8.66)$ \\
\hline Total & & $19.83(5.35)$ & $17.50(6.19)$ & $16.97(6.32)$ & $17.36(6.57)$ & $15.73(6.72)$ & $16.07(6.81)$ \\
\hline
\end{tabular}

Post hoc test results showed statistically significant difference in hearing level between most groups in all frequencies except between (Eustachian tube disease \& occluding earwax).

PTA = pure tone audiometry; $S D=$ standard deviation. 
affection), while all the remaining had conductive problems as a cause of loss. Hussein found that $1.8 \%$ of the $10 \%$ of his study sample with hearing impairment had sensorineural hearing loss [17].

Ear infection is a common childhood illness and can negatively impact speech development. In Native American children, the estimated incidence of middle ear disease in the general childhood population is around 5\%, but for poor children, the incidence is reported to be closer to $20 \%$ or $25 \%$ [19]. While we did not assess socioeconomic status of the children, in general the South Sinai population is not affluent.

Secretory otitis media was the most common finding in our children tested. It was found in $10.4 \%$ of all ears examined. It is considered in some reports as the commonest cause of childhood hearing loss in developing countries [20]. Studies from Malaysia, India, Nigeria and Egypt have reported prevalence rates of $13.8 \%-36.2 \%$ among comparable school-aged populations [4,21-23]. The principal risk factors for secretory otitis media are usually poor hygiene, poor nutrition, poor housing conditions, viral/bacterial infection and upper respiratory allergy [20]. Although secretory otitis media has different pathophysiological features, its associa ated hearing loss is typically in the slight to mild range (mean $25 \mathrm{~dB} \mathrm{HL}$ ) and more obvious in low frequencies.

In our study, impacted earwax was detected in $9.5 \%$ of the children. Although the effect on hearing was only minimal and involved mainly low frequencies, it is misleading to presume that hearing loss related to impacted earwax is the only cause and will resolve after removal of the wax.

The lack of correlation between hearing loss, history of hearing difficulties and ear discharge has been reported before by Rosenfield and his coworkers [24]. In our study, chronic suppurative otitis media with perforation was found in only $0.4 \%$ of the study group, although it caused the worst mean hearing level of all other problems.

This is the first study to examine ear and hearing disorders in a remote governorate in Egypt among a large sample representative of the governorate and provides an indication of the extent of the problem. While the majority of children had normal hearing and only a very small percentage had moderate or severe hearing loss, none of the children with hearing impairment had been previously diagnosed and nor were receiving treatment and support. Given the adverse consequences hearing impairment can have on educational attainment, the Ministry of Health should focus on hearing and middle ear screening at schools for the early detection and management of middle ear and hearing problems. Teachers also need to be made aware of the compound impact such a loss can have on learning.

\section{References}

1. Lee DJ, Gomez-Marin O, Lee HM. Prevalence of childhood hearing loss: the Hispanic Health and Nutrition Examination Survey and the National Health and Nutrition Examination Survey II. American Journal of Epidemiology, 1996, 144:442-449.

2. Melissa W et al. Slight/mild sensorineural hearing loss in children. Pediatrics, 2006, 118:1842-1851.

3. Olusanya BO, Okolo AA, Aderemi AA. Predictors of hearing loss in school entrants in a developing country. Journal of Postgraduate Medicine, 2004, 50:173-179.

4. Olusanya BO, Okolo AA, Ijaduola GT. The hearing profile of Nigerian school children. International Journal of Pediatric Otorhinolaryngology, 2000, 55:73-79.

5. Abdel-Rahman AG et al. Prevalence and risk factors for hearing disorders in secondary school students in Ismailia, Egypt. Eastern Mediterranean Health Journal, 2007, 13(3):586-594.

6. Environmental SS, Profile D. Cairo, Ministry of State for Environmental Affairs \& South Sinai Governorate, 2003.

7. Dawson-Saunders B, Trapp RG. Basic and clinical biostatistics, 2nd ed. Norwalk, Connecticut, Appleton \& Lange, 1994.

8. Niskar AS et al. Prevalence of hearing loss among children 6-19 years of age: the 3rd national health and nutrition examination survey. Journal of the American Medical Association, 1998, 279:1071-1075.

9. American Speech-Language-Hearing Association. Type, degree, and configuration of hearing loss (http://www.asha.org/ public/hearing/disorders/types.html, accessed 2 February 2012).

10. Haddad JJr. The ear. In: Kliegman RM et al., eds. Nelson textbook of paediatrics, 18th ed. New York, Elsevier, 2007:2617-2646.
11. Thompson MD, Thompson G. Early identification of hearing loss: listen to parents. Clinical Pediatrics, 1991, 30:77-80.

12. Bess FH, Dodd-Murphy J, Parker RA. Children with minimal sensorineural prevalence, educational performance and functional status. Ear and Hearing, 1998, 19:339-354.

13. Zakzouk SM, Al-Anazy F. Sensorineural hearing impaired children with unknown causes: a comprehensive etiological study. International Journal of Paediatric Otorhinolaryngology, 2002, 64(1):17-21.

14. Abolfotoh MA, Ghieth MM, Badawi IA. Hearing loss and other ear problems among schoolboys in Abha, Saudi Arabia. Annals of Saudi Medicine, 1995, 15:323-326.

15. Riad S. A study of the hearing status of school children in Alexandria Governorate [MD thesis]. Alexandria, University of Alexandria, 1975.

16. Kolta O. The hearing profile of subjects in a rural community in Qualyb area [MD thesis]. Cairo, Ain Shams University, 1982.

17. Hussein N. Prevalence of hearing loss among school children in Ismailia governorate [Master thesis]. Cairo, Ain Shams University, 1996.

18. Abdel-Hamid $\mathrm{O}$ et al. Prevalence and patterns of hearing impairment in Egypt: a national household survey. Eastern Mediterranean Health Journal, 2007, 13(5):1170-1180.

19. Rao RS et al. Hearing impairment and ear diseases among children of school entry age in rural South India. International Journal of Pediatric Otorhinolaryngology, 2002, 64:105-110.

20. Prevention of hearing impairment from chronic otitis media. Report of a WHO/CIBA Foundation Workshop, London, 19-21 
November 1996. Geneva, World Health Organization, 1998 (WHO/PDH/98.4).

21. Mourad MI, Farghaly NF, Mohammed HG. Hearing impairment: Is it a public health problem among school pupils in Alexandria. Journal of the Egyptian Public Health Association, 1993, 68:703-726.

22. Jacob A et al. Hearing impairment and otitis media in rural primary school in South India. International Journal of Pediatric Otorhinolaryngology, 1997, 39:133-138.
23. Saim A et al. Prevalence of otitis media with effusion amongst pre-school children in Malaysia. International Journal of Pediatric Otorhinolaryngology, 1997, 41:21-28.

24. Rosenfeld RM, Goldsmith AJ, Madell JR. How accurate is parent rating of hearing for children with otitis media? Archives of Otolaryngology--Head \& Neck Surgery, 1998, 124:989-992.

\section{The primary ear and hearing care training resource}

The primary ear and hearing care training resource is a set of four training manuals developed by WHO that are aimed at equipping primary health care workers in developing countries with simple and effective methods to reduce the burden of ear and hearing disorders.

Although half of all deafness and hearing impairment is avoidable, an estimated 278 million people worldwide are living with disabling hearing impairment (moderate or worse level of hearing loss in the better hearing ear). Many more have mild hearing loss and/ or ear diseases. One quarter of hearing impairment begins during childhood, and $80 \%$ of all deaf and hearing impaired people live in low and middle income countries. These often life-long and sometimes life-threatening problems may have profound effects on: interpersonal communication, education, employment, social relationships and through stigmatization. They produce substantial economic burdens on countries.

The primary ear and hearing care training resource addresses the urgent need for action to prevent and manage ear diseases and hearing impairment. The manuals provide practical information and guidance and can be used as part of a training course, standalone training module or in a self-taught manner. They are designed to be useful to a wide range of primary health care personnel. The manuals can also be used to help communities understand common causes of deafness and hearing impairment and ways to prevent and/or treat the conditions. 